\title{
STRIVING TO RESTRAIN EMPLOYEE TURNOVER INTENTION THROUGH ETHICAL LEADERSHIP AND PRO-SOCIAL RULE BREAKING
}

\author{
Nauman Majeed $^{a *}$, Samia Jamshed $^{\mathrm{a}}$, Norizah Mohd Mustamil ${ }^{\mathrm{a}}$ \\ ${ }^{a}$ Faculty of Business \& Accountancy, University of Malaya \\ *Corresponding Author Email: nauman@siswa.um.edu.my
}

\begin{abstract}
The increased turnover intention of employees has always been a dilemma for organizations. This is not only affecting the working standards of institutions but is also depriving them of thequalified and talented workforce. Turnover intention can be represented as the movement of a person from an institution across its membership boundary. Talented, highly qualified and satisfied academicians are required for the prosperity of any higher education institution. If the academicians are not motivated and satisfied with the job, the working standards in the educational institutions will fall and due objectives won't be accomplished. Ethical leadership assumes a fundamental part of decreasing turnover intentions among employees. The aim of this study is to investigate the effect of ethical leadership on employee turnover intentions through the lens of pro-social rule breaking in private sector higher education institutions of Pakistan. Correlation and regression were employed in order to test the model where survey responses were gathered from 240 academicians employed in four private sector universities of Pakistan. Results showed that there exists a negative relationship between ethical leadership and employee turnover intention and prosocial rule breaking. Furthermore, pro-social rule breaking has a positive relationship with employee turnover intention. The results of regression analysis showed that prosocial rule breaking acts as a partial mediator between ethical leadership and employee turnover intentions. Expanding on current theoretical knowledge, this study makes a significant contribution to leadership literature suggesting that firms should implement ethical leadership practices that support in reducing employee turnover intentions.
\end{abstract}

Keywords: Ethical Leadership, Employee Turnover Intention, Pro-Social Rule Breaking, Private higher education institutions

\section{INTRODUCTION}

Organizations across the world make progress towards competitiveness in order to improve the performance of their business. In contemporary business operations, retaining the talented workforce has become a critical issue (Amankwaa \& AnkuTsede, 2015). According to Bajwa, Yousaf and Rizwan (2014) the colossal rise in the turnover intention of employees has not only gained the attention of various researchers but has also become a topic of debate for domestic and multinational associations whether private or public sector.

Pakistani firms additionally are confronting the real problem of increased attrition rate (Sabir, Sohail, \& Khan, 2011). On one side denying the associations from the 
skilled and qualified workforce, and on the other side, influencing the standards of working in these associations (Shah \& Khan, 2015). The fact that higher education institutions play an integral part in the socio-economic development of a country cannot be denied. The prosperity of an educational institution to achieve their goals requires a talented and highly qualified workforce. It has been observed that in the services sector of Pakistan there is high turnover rate and the vast majority of the employees possess intention to leave (Shah \& Khan, 2015). In the education sector, employees quickly change their jobs because of low compensation and disappointment about work, poor supervision, promotion and work culture (Shah \& Khan, 2015).

Various components that can be accountable for the increase in the attrition rate of the employees include employee discernment, reduced job satisfaction, injustice in the organizations, macho culture, financial pressures and so forth (Nasir \& Bashir, 2012). In any case, one of the imperative precursors of employees' turnover intention is leadership style (Amankwaa \& Anku-Tsede, 2015; Mayer, Aquino, Greenbaum, \& Kuenzi, 2012). The importance of ethical leadership in diminishing employee turnover intentions and workplace deviance conduct is clarified by a few researchers (e.g. Holtom, Mitchell, Lee \& Eberly, 2008; Mayer et al., 2012).

The research study by Elçi, Şener, Aksoy and Alpkan (2012) has highlighted the significance of ethical leadership in decreasing turnover intentions among employees. Moreover, Past studies have revealed that role models in the organizations impact pro-social practices (e.g. Mayer et al., 2012; Piccolo, Greenbaum, Hartog \& Folger, 2010) citizenship behaviors (Majeed, Nor, \& Mustamil, 2017) destructive deviant workplace behaviors (Van Gils et al., 2015) and team effectiveness (Jamshed, Nor, \& Bakar, 2017). In light of these contentions, leaders who behave as role models have an imperative part of cultivating positive behaviors and averting turnover intentions (Demirtas \& Akdogan, 2014).

Display of positive attitude and interaction with subordinates, such as treating them with respect and sincerity is the hallmark of ethical leaders that makes them attractive role models (Walumbwa, Hartnell \& Misati, 2017). Institutions turn out to be more significant when the display of behavior by the leaders is morally upright (Wong \& Page, 2003). Furthermore, compelling leadership (Khan, Khan \& Chaudhry, 2015) alongside work atmosphere displaying ethical and positive pro-social behaviors (Mayer et al., 2012; Piccolo et al., 2010) assumes a fundamental part in declining turnover intentions among employees.

Pakistani services sector organizations are experiencing the problems of the unusual state of withdrawal intentions because of absence of ethical work atmosphere (Kumar, Ramendran \& Yacob, 2012) work engagement (Javed et al., 2014), and alignment with the values of organizations (Nasir \& Bashir, 2012). It is critical for workers in the service sector to discover reason and importance in their occupations and be lined up with values of the organization in an effort to decrease turnover intentions (Iqbal, Arif \& Badar, 2012). Consequently, this study aims at recognizing the significant importance of ethical leadership in decreasing turnover intentions of employees in higher education private sector universities of Pakistan through the lens of pro-social rule breaking. 


\section{LITERATURE REVIEW}

\section{Ethical Leadership}

Ethical leadership is a rising approach of leadership that alludes to the presentation of normatively right practices by means of social connections and individual activities, and the display of these practices through open correspondence, fortification, and feeling of basic leadership among supporters (Brown, Treviño \& Harrison, 2005). Ethical leaders assume an awesome role in advising and portraying the ethical conduct of employees in organizations. Ethical leaders work with trustworthiness, they are honest and reliable with high standards of integrity and moral values (Johnson, 2017). They seek social standards, values and are transparent in managing their work and individuals.

They make professional and ethical decisions. Leaders experience tensions between competing elements of leadership, management, and administration (Adams, Kutty, \& Zabidi, 2017). In addition, it has been found in the literature that ethical leadership assumes an extraordinary part in yielding critical number of positive results, for example, the ethical atmosphere of association (Schaubroeck, Lam \& Peng, 2011), employee performance (Piccolo et al., 2010) citizenship behavior of employees (Kacmar et al., 2011), and enhancing group learning behavior (Walumbwa et al.,2017). Ethical leadership is related to trust, integrity, moral development, fairness, and charisma. Personal adherence to ethical institutional norms, expressing concern for the best interest of employees and stimulating them to reciprocate in the same manner make ethical leaders as credible role models.

\section{Employee Turnover Intention}

In spite of accepting tremendous consideration from researchers, turnover remains a prime concern of organizations. Holtom et al. (2008) noted despite the fact that more than 1500 scholarly work had endeavored to clarify turnover yet at the same time being expensive in terms of time and cost it remains a dynamic area of research. As per Perez (2008), the expression "turnover implies leaving or quitting the job". Similarly, Mobley (1977) expressed that when an employee intentionally leaves the association it refers to turnover and it has been a persevering problem across the associations. The noteworthy reasons behind employee turnover intention involve an external opportunity, limited growth and promotional opportunities within the organizations and further educational opportunities.

The related literature has identified many contributing components leading to turnover, for example, work disappointment and inadequate leadership (Bull, 2010). In this specific situation, the significance of the act of ethical leadership cannot be disregarded. Kaur and Pankaj (2013) have studied that organizational justice, job stress, job satisfaction and quality of work life are identified as the predecessors of turnover intention.

\section{Pro-Social Rule Breaking}

The paradigm of pro-social rule breaking was introduced by Morrison in 2006. Prosocial rule breaking has been referred to a situation where an employee intentionally disrupts the organizational rules and standard operating procedures with the objective of upholding organizational as well as stakeholder's interest. The term pro- 
social rule breaking was coined initially by Morrison (2006) describing it as a nonselfish act where employee deliberately and willingly serves the benefit of the institution and its partners by violating or going against formal institutional policies, rules, and regulations.

According to Spreitzer and Sonenshein (2004), the phenomenon of positive deviance can better clarify the concept of pro-social rule-breaking as practices in which employees display good intentions for the association and its partners regardless of results. Hence, Pro-social rulebreaking as constructive deviance (Xu, \& Zhu, 2017) can be referred as an occasion when an employee working in an organization intentionally disrupt, breaks or violates a rule, policy or a regulation with an intent in mind that this is in the larger interest and welfare of the organization. In nutshell, breaking of a formal organizational rule with good intentions.

\section{Relationships among the constructs}

Since leadership assumes a fundamental role in driving or repressing workplace deviance conduct. In particular, one of the significant explanations for deviance of employees in organizations is the absence of ethical leadership practices (Thau et al., 2009). The study by Van Gils et al. (2015) explored how ethically mindful employees act in a situation while working with unethical leaders. The findings uncovered that ethically mindful employee's display high workplace deviant behavior towards the unethical leader.

To comprehend the impact of ethical leadership on negative as well as positive workplace deviance and turnover intention of employees, social learning theory can be utilized (Mayer et al., 2012). Ethical leaders have a tendency to be appealing, solid, and set examples for subordinates to follow (Brown \& Treviño, 2006). While seeing appropriate conduct showed by ethical leaders, subordinates have a tendency to copy those practices. The more subordinates figure out how to act appropriately from their ethical leaders, the more improbable they are to participate in negative conduct.

In a study utilizing a sample of 224 employees from 18 institutions by Neves and Story (2015) found that ethical leadership is positively related to employee engagement especially when the reputation of supervisor in terms of performance execution is high, which in turn is related with reduced negative deviance. The study of Ethical Leadership conducted in Pakistani institutions showed a noteworthy and negative association with negative deviance (Aabdeen et al., 2016). Followers' behavior have a tendency to encourage pro-social execution (Youli, Xixi \& Xi, 2014). In light of the findings of conceivable connections among the variables, the following hypotheses were articulated.

\section{Hypotheses}

H1: Ethical leadership has a negative relationship with the turnover intention of employees.

H2: Ethical Leadership has a positive relationship with pro-socialrule breaking.

H3: Pro-Social Rule Breaking is positively related to turnover intention. 
H4: The relationship between ethical leadership and employee turnover intention is mediated by pro-social rule breaking.

\section{Theoretical Framework}

As appeared in figure 1, two main theories which support the underpinning of this study are (1) Social Exchange theory (SET) and (2) Social Learning Theory (SLT). SET provides proof to clarify the idea of connection between the type of leadership and turnover intentions. SET proposes that exchange process stimulates social behavior of individuals (Homans, 1958). At the point when individuals see that they are dealt decently, the standard of reciprocity says that they ought to reciprocate.

In this way, individuals incite various types of positive results for association or its leader, for example, spirit at work, work engagement, work involvement, job commitment and OCB (Cropanzano \& Mitchell, 2005). Whereas, when individuals see that they are not treated decently, they show various types of practices, for example, turnover intention, disappointment, work burnout and negative work environment deviance practices (Cropanzano \& Mitchell, 2005). Referring to this study the venture of the firm regarding offering ethical leadership may decrease turnover because of extended commitment.

Social learning theory is progressively utilized for the promotion of attractive behavioral change (Muro \& Jeffrey, 2008). This theory depends on the possibility that individuals learn from their interaction with others in a social setting. SLT has turned into the most intense theory of learning and improvement. The process of leadership includes affecting and convincing employees (Yukl, Mahsud, Hassan \& Prussia, 2013). Through relational connections, managers promote ethical leadership thereby convince and persuade employees (Brown et al., 2005). Leaders play a vital role in effective role modeling of employees.

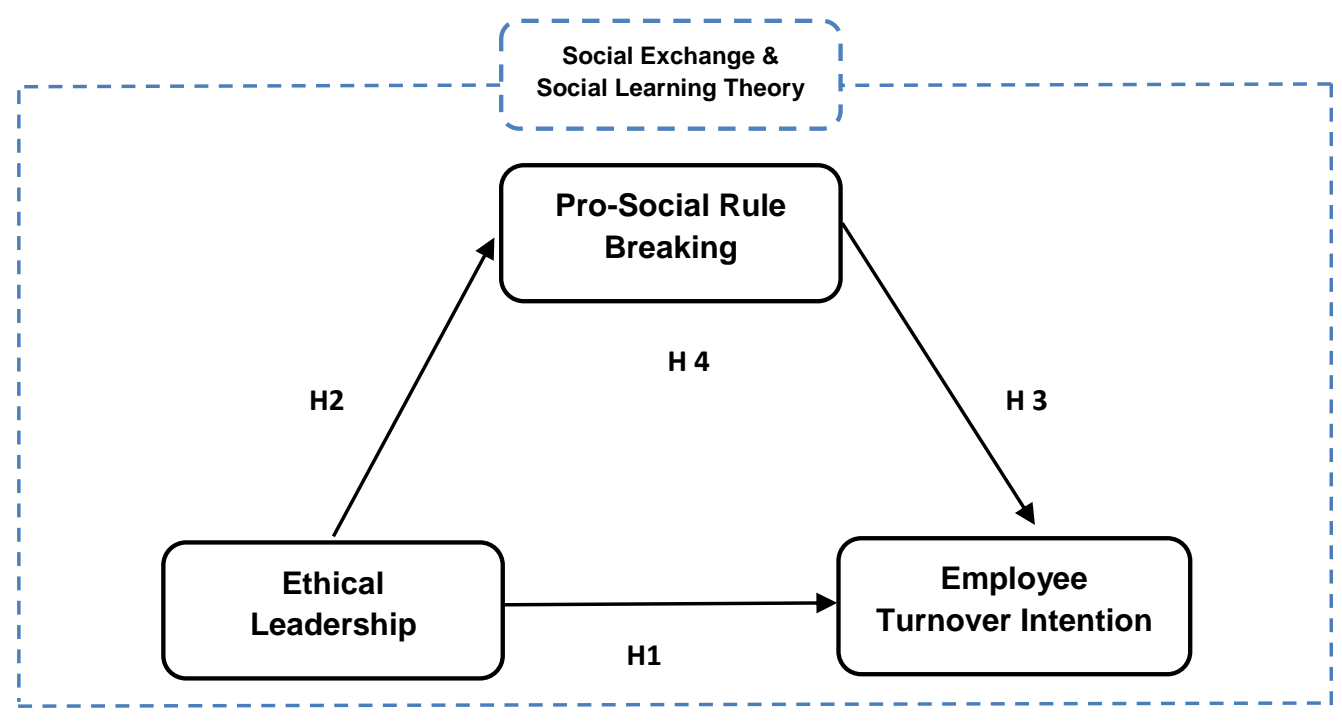

Figure 1: Theoretical Framework

\section{METHODOLOGY}

The present research has used the quantitative method of gathering and interpreting data to produce results. Keeping in view the fact that turnover intentions of 
academicians working in educational institutions adversely affect the performance of institutions, this investigation is focusing on the population of higher education institutions of Pakistan. The study is carried out to comprehend whether ethical leadership influences turnover intentions of academicians working in private universities. As per scope of this study, the unit of analysis utilized is individuals (academicians) of private sector higher education establishments. SPSS 22 is utilized to carry out the statistical analysis of the data.

\section{Operationalization of variables (Measures)}

The structured questionnaire consists of 37 items was employed to gather the responses. Respondents were requested to rate the items by using five-point Likert scales that ranges from $1=$ "strongly disagree" to $5=$ "strongly agree". Refer to Table 1.

Table 1: Research Instruments

\begin{tabular}{lcl}
\hline \multicolumn{1}{c}{ Constructs } & No of items & Measurement Scales \\
\hline Ethical Leadership & 10 & Brown et al. (2005) \\
Pro-Social Rule Breaking & 13 & Dahling et al. (2012) \\
Turnover Intention & 14 & Jacobs and Roodt (2008) \\
\hline
\end{tabular}

\section{Methodology and Procedure}

To check the internal consistency of instrument; a pilot study was conducted. Permanent faculty members from 5 departments of a private sector university were requested to fill the study questionnaire. Forty valid responses were received. The reliability measurements for ethical leadership, pro-socialrule-breaking and turnover intention through the test of Cronbach's alpha are recorded as ethical leadership (0.87), pro-socialrule-breaking (0.81), and turnover intention (0.83) indicating the acceptable internal consistency of the items. As per George and Mallery (2003) values of Cronbach alpha under 0.5 are not satisfactory while values more prominent than 0.7 are adequate, values higher than 0.8 are viewed as good and values over 0.9 are viewed as excellent.

Self-reported questionnaires were circulated in person among 275 academicians working in four private sector universities of Lahore, Pakistan. The research objectives were outlined in a cover letter to facilitate respondents and to maintain the confidentiality of their responses was mentioned. Among the 275 questionnaires distributed by using convenience sampling design, 247 questionnaires were returned out of which 240 were found to be valid, yielding a response rate of $86 \%$. Details of the response rate for each university are provided in table 2. During data preparation, respondents were identified with their universities and universities were coded as institution 1-4 respectively.

Table 3 depicts the demographic characteristics explaining that out of 240 selfreported questionnaires that were returned, $64 \%$ of the respondents were males and $36 \%$ were females. Considering an educational level $79 \%$ of the participants had an MS/M.Phil degree, $18 \%$ held a doctoral degree and 3\% held a master's degree. Under 
the category of the position held $51 \%$ of participants were lecturers, $18 \%$ were senior lecturers, $19 \%$ were assistant professors, $7 \%$ were associate professors and $5 \%$ of participants held the position of professor.

Table 2: Questionnaires distributed and Response Rate

\begin{tabular}{lccc}
\hline Universities & $\begin{array}{c}\text { Questionnaires } \\
\text { distributed }\end{array}$ & $\begin{array}{c}\text { Questionnaires } \\
\text { received (Valid) }\end{array}$ & Response Rate \\
\hline Institution 1 & 75 & 71 & $94 \%$ \\
Institution 2 & 72 & 61 & $84 \%$ \\
Institution 3 & 63 & 52 & $82 \%$ \\
Institution 4 & 65 & 56 & $86 \%$ \\
Total & 275 & 240 & $87 \%$ \\
\hline
\end{tabular}

Table 3: Demographic Characteristics

\begin{tabular}{lc}
\hline Variables & Total \\
\hline Gender & $153(64)$ \\
Male & $87(36)$ \\
Female & \\
Age & $35(15)$ \\
$20-25$ & $78(32)$ \\
$26-30$ & $80(33)$ \\
$31-40$ & $47(20)$ \\
40 \& above & \\
Education Level & $8(3)$ \\
Master Degree & $190(79)$ \\
MS/M.Phil Degree & $42(18)$ \\
Philosophy of doctor & \\
Position Held & $122(51)$ \\
Lecturer & $45(18)$ \\
Senior Lecturer & $46(19)$ \\
Assistant Professor & $16(7)$ \\
Associate Professor & $11(5)$ \\
Professor & \\
Organization Tenure & $88(36)$ \\
1-5 years & $90(38)$ \\
6-10 years & $62(26)$ \\
More than 11 years &
\end{tabular}

Note: Data presented as (\%)

\section{RESULTS}

\section{Descriptive Statistics and Correlation Analysis}

The mean values of ethical leadership, employee turnover intention, and pro-social rule breaking are 3.97, 3.86 and 2.19, respectively as demonstrated in Table 4 . The standard deviation is utilized to demonstrate that the values are purposeful around the mean displaying normal distribution for all variables. Lower values of standard deviation justify the reliability of mean. The standard deviation values of ethical 
leadership, employee turnover intention, and Pro-Social Rule Breaking are 0.83, 1.03 and 0.87 .

Table 4: Descriptive statistics - Variables Mean and Standard Deviations

\begin{tabular}{lccccc}
\hline & $\mathrm{N}$ & Minimum & Maximum & Mean & Std. Deviation \\
\hline Ethical Leadership & 240 & 1.00 & 5.00 & 3.9735 & 0.83075 \\
Pro-Social Rule Breaking & 240 & 1.00 & 5.00 & 2.1928 & 0.87023 \\
Employee Turnover Intention & 240 & 1.00 & 5.00 & 3.8648 & 1.0324 \\
Valid N (listwise) & 240 & & & & \\
\hline
\end{tabular}

A measure of the relationship between two continuous variables can be characterized as Correlation Analysis which is used to determine the direction and size of relationships among two variables. Pearson correlation coefficient has been utilized in this study to analyze the data. Values of correlation analysis are shown in Table 5.

Table 5: Correlations Analysis Results

\begin{tabular}{|c|c|c|c|c|}
\hline & & $\begin{array}{l}\text { Ethical } \\
\text { leadership }\end{array}$ & $\begin{array}{l}\text { Pro-social } \\
\text { rule breaking }\end{array}$ & $\begin{array}{c}\text { Employee } \\
\text { turnover } \\
\text { intention }\end{array}$ \\
\hline \multirow[t]{4}{*}{ Ethical Leadership } & Pearson & & & \\
\hline & Correlation & 1 & -.071 & $-.413^{* *}$ \\
\hline & Sig. (2-tailed) & & .181 & .000 \\
\hline & $\mathrm{N}$ & 240 & 240 & 240 \\
\hline \multirow{4}{*}{$\begin{array}{l}\text { Pro-social rule } \\
\text { breaking }\end{array}$} & Pearson & & & \\
\hline & Correlation & -.071 & 1 & $.274^{* *}$ \\
\hline & Sig. (2-tailed) & .181 & & .000 \\
\hline & $\mathrm{N}$ & 240 & 240 & 240 \\
\hline \multirow{4}{*}{$\begin{array}{l}\text { Employee turnover } \\
\text { intention }\end{array}$} & Pearson & & & \\
\hline & Correlation & $-.413^{* *}$ & $.274^{* *}$ & 1 \\
\hline & Sig. (2-tailed) & .000 & .000 & \\
\hline & $\mathrm{N}$ & 240 & 240 & 240 \\
\hline
\end{tabular}

**Correlation is significant at the 0.01 level (2-tailed)

A Pearson correlation is calculated in Table 5 to evaluate the relationship between ethical leadership (independent variable), employee turnover intention (dependent variable) and pro-social rule breaking (mediating variable). There exists a statistically significant negative correlation between ethical leadership and employee turnover intention $(r=-0.413, n=240, p=0.000)$, thereby accepting hypotheses one. The correlation analysis of hypothesis two reveals statistically significant negative correlation between ethical leadership and pro-social rule breaking $(r=-0.071, n=$ $240, p=0.181$ ), consequently, hypothesis two is rejected. Further there exists a statistically significant positive correlation between pro-social rule breaking and 
employee turnover intention $(r=0.274, n=240, p=0.000)$. Hence hypothesis three is accepted.

\section{Hierarchical Regressions}

Multiple regression analysis has been used for testing the mediation hypotheses to examine whether Pro-Social Rule Breaking plays a mediating role between Ethical Leadership and Turnover Intention. Table 6 represents the values of multiple regression analysis. To run the regression analysis in addition to studying constructs, control variables were also added to test each hypothesis. In the first step, age, gender, education level, a position held and organizational tenure were entered as control variables. In second step predictor variable ethical leadership was entered. Results of the examination demonstrate that $R$ square estimation of 0.178 shows that $17.8 \%$ of employee turnover intention can be anticipated from the ethical leadership. Considering the causal impact of ethical leadership, 0.553 units decrease in ethical leadership prompts 1 unit increase in the turnover intention. Henceforth the values $\left(R^{2}=0.178, \beta=0.553, p<0.05\right)$ proposes that hypotheses one is accepted.

Table 6: Multiple Regression Analysis with Ethical Leadership regressed on Employee turnover intention through mediation of Pro - social rule breaking

\begin{tabular}{|c|c|c|c|c|c|}
\hline Model & Dependent ${ }^{`}$ & $\begin{array}{l}\text { Independent } \\
\text { variable(s) }\end{array}$ & $\mathbf{R}^{2}$ & $\Delta R^{2}$ & B \\
\hline \multirow[t]{2}{*}{1} & ETI & i) CVs & .11 & .11 & \\
\hline & & ii)CVs+ EL & .178 & .176 &.$- .553^{*}$ \\
\hline \multirow[t]{2}{*}{2} & PSRB & i)CVs & .04 & .04 & \\
\hline & & ii)CVs+ EL & .007 & .005 & $-.067 *$ \\
\hline \multirow[t]{2}{*}{3} & ETI & i) $\mathrm{CVs}$ & .15 & .15 & \\
\hline & & ii) $C V s+P S B$ & .071 & .069 & $.299 *$ \\
\hline \multirow[t]{3}{*}{4} & ETI & i)CVs & .11 & .11 & \\
\hline & & ii)CVs+EL & .178 & .176 & $-.553^{*}$ \\
\hline & & PSB & .231 & .229 & $.317^{*}$ \\
\hline \multicolumn{6}{|c|}{$\begin{array}{l}\mathrm{CV}=\text { Control Variables; } \mathrm{ETI}=\text { Employee Turnover Intentions; PSRB= Pro-Social Rule } \\
\text { Breaking; EL= Ethical Leadership } \\
\text { Control Variables= Gender, Education level, Age, Position Held, Organizational } \\
\text { Tenure }\end{array}$} \\
\hline
\end{tabular}

To test the second hypotheses pro-social rule breaking was entered with control factors. The result of $\left(R^{2}=0.007, \beta=0.067, p<0.05\right)$ demonstrated that pro-social rule breaking has an inverse relationship with ethical leadership as 0.067 units decrease in ethical leadership prompts 1 units to increase in the Pro-social rule breaking. Considering the third hypotheses pro-social rule breaking clarified a positive variation in Employee Turnover Intention $\left(R^{2}=0.71, \beta=0.299, p<0.05\right)$ clarifying 0.299 units increase in Pro-Social Rule Breaking prompts 1 unit increase in the turnover intention supporting the hypotheses.

To investigate the mediating role of "Pro-social rule breaking" among ethical leadership and turnover intention-behavior of employees, in addition, Baron and Kenny (1986) regression analysis procedure is utilized. The result of the first step, which explains that when ethical leadership is entered, this account for $17.8 \%$ variation in turnover intention-behavior of employees $\left(R^{2}=0.178\right)$. Additionally, when 
pro-social rule breaking is added, then variation account for $23.1 \%$ in the dependent variable $\left(R^{2}=0.231\right)$. In the second step, when pro-social rule breaking is added into the existing model, it causes an additional increase in turnover intention-behavior of employees $\left(\triangle R^{2}=0.049, p<0.05\right)$. This explains that pro-social rule breaking contributes significantly to employee turnover intention. But this variation is less than accounted by the ethical leadership indicating the partially mediated role of pro-social rule breaking. Thus, out of four tested hypotheses, three hypotheses are supported except hypotheses two.

\section{DISCUSSION}

Since high turnover intention among employees of services organizations of Pakistan is an important issue of inquiry, this study aimed at examining the nature of the relationship between ethical leadership and employee turnover intention through the lens of pro-social rule breaking in higher education institutions. The correlation analysis showed that ethical leadership is negatively related to the turnover intention of employees $(r=-0.413)$ and pro- socialrule breaking $(r=-0.71)$ whereas, Pro-social rule breaking has a positive correlation with employee turnover intention ( $r=.274)$. The outcome of the study can be defended in the context of institutions which have a low level of employee engagement, reduced job satisfaction, incapable leadership and occupation fulfillment that brings about higher turnover intentions among employees. At the point when leaders display ethical behavior, a solid sound culture thrives which result in bringing down turnover intentions. This exploration finding is steady with few examinations conducted globally as well as in Pakistani setting (Elçi et al., 2012; Yemi-Sofumade, 2012; Aabdeen et al., 2016) that reduced turn over intention among employees is caused by display of ethical leadership. As the study is carried out in the education sector which is part of the services sector. Thus, the findings are consistent with the study of Aabdeen et al. (2016).

The negative correlation of hypotheses two is inconsistent with the proposed hypothesis in the Pakistani context. In a global setting, positive relationship of prosocial rule breaking has been observed with transformational leadership (Youli et al., 2014). Great leaders provide productive criticism to their subordinates, persuade devotees to display additional exertion and urge supporters to ponder complex problems. Subsequently, supporters have a tendency to carry on in ways whichinspire pro-social execution (Youli et al., 2014). Though the phenomenon is well established in western settings (Youli et al., 2014; Dahling et al., 2012) isn't valid in Pakistani setting. The finding of this study has uncovered that institutions which display high standards of ethical leadership may bring about diminishing pattern of pro-social rule breaking exercises. This interesting result which has deviated from the expectations may be clarified by the absence of comprehension of pro-social rule breaking idea in Pakistani associations.

It can be derived that when role model leaders in Pakistani associations are sound ethically then supporters are more averse to go astray from formal rules and regulations for the effective functioning of the institution. This finding of the study isn't consistent with the current literature. A few reasons that can justify this deviation of the result. Firstly, in Pakistani firms, there is a lack of awareness among employees regarding the concept of pro-social rule breakingis relatively a new term. Furthermore, social and cultural contrast amongst the western and asian nations may likewise clarify this distinction. In western nations, employees are probably going to 
feel more enabled and, in this manner, they break the formal rules and policies for the advancement of association. Whereas, in Pakistani culture, employees are not keen on breaking hierarchical rules for the interest of the organization even ethical leadership behavior is seen in the institution. Therefore, it can be assumed that the cultural difference between western countries and Pakistan has resulted in such a difference. Since, the major focus of ethical leadership is more on morals, uprightness, and integrity and less on empowerment of employees in their work resulting in an insignificant relationship with pro-social rule breaking in Pakistani education sector. The finding of the investigation uncovers that in Pakistani setting pro-socialrule breaking activities prompts higher turnover intention among employees. This research significantly adds to the literature being a pioneerin measuring the relationship between ethical leadership and turnover intentionmodeling pro-social rule breaking as mediator.

\section{THEORETICAL AND PRACTICAL IMPLICATIONS}

The study provides theoretical support to the existing literature by providing empirical evidence to the extent of pro-social rule breaking on the relationship between ethical leadership and employee turnover intention. Despite earlier investigations evaluating the relationship of ethical leadership and turnover intention among employees, however, no strong comprehension is accessible to clarify how it functions in the real world. This study investigates and affirmed that pro-social rule breaking partially mediates ethical leadership and turnover intention relationship. Secondly, this examination has distinguished the positive part of ethical leadership in diminishing turnover intention among employees in education segment of Pakistan. The study suggests administrators select ethical leaders by employing rigorous selection strategies which enable them to detect moral standards, caring aptitude, level of integrity and other ethical conduct.

Moreover, the leader should be trained in practicing the ethical leadership by providing them awareness and significance of being ethical role models, prominence of ethical practices, rewarding consequence by the ethical performance of employees and guide employees to be ethical in the work place. For enduring ethical leadership and rationale for pro-social rule breaking behavior, the seminars identifying the importance of such practices should be arranged to bring positive results. Lastly, this study might be valuable for both public and private sector organizations working in Pakistan. The conclusions drawn from this study will certainly facilitate the institutional leaders, academicians, and mentors in acknowledging that employee turnover intention can be reduced by ethical leadership. This examination adds to the existing literature and body of knowledge explaining the phenomena of prosocialrule breaking as a mediator of ethical leadership and employee turnover intention which is scarce in the current literature.

\section{STUDY LIMITATIONS}

Though the study has several theoretical and practical implications, the research is subject to the following limitations. Firstly, due to the limited time and resources, the data was collected from the employees working in the educational institutions of private sector only. Secondly, the scope of the study is limited to the constructs of the study and could not explore the other organizational features of employee 
satisfaction, employee engagement and extent of organizational justice which may have an influence on ethical leadership and employee turnover intention.

Therefore, the other factors influencing the employee turnover intention and prosocial rule breaking should be explored in future studies. Further employing the crosssectional study design, the study could not make inferences for causal relationships by collecting data in different time horizons and relies on self-reported already developed instruments for data collection. Lastly, the results of the study could not be generalizable to other services sector as this study is limited to the educational services of just one country.

\section{RECOMMENDATIONS FOR FUTURE RESEARCH}

The future inquiries may be carried out in different sectors to include health care, banking, manufacturing, police and military regiments to study the role of ethical leadership on turnover intentions and also to study exclusively on pro-social rule breaking. Additionally, the future examinations can comprehend the role of other styles of leadership i.e. transformational leadership, transactional leadership, spiritual leadership and charismatic leadership in lessening turnover intentions of employees in another Pakistani setting. Furthermore, to fill the gap in existing research, similar studies can be conducted by incorporating moderating or mediating variables such as Organizational virtuousness, Citizenship behaviors, employee engagement, ethical work climate, knowledge sharing, emotional intelligence, organizational culture, and trust.

For future research qualitative techniques using interpretivist paradigm to include interviews, focus group and other subjective strategies should be employed. This will help in finding the relationship between these unique variables through a different worldview. Likewise, this investigation can be repeated in other social settings by doing it in different nations to expand the generalizability of study findings. Future research can also look into the longitudinal or experimental design to create more significant inferences about causality amongst factors. The future examinations can reproduce a similar study in some other corporation or industry setting in Pakistan to see the resemblance or distinction of results.

\section{REFERENCES}

Aabdeen, Z., Khan, M. N., Khan, H. G., Farooq, H. Q., Salman, M., \& Rizwan, M. (2016). The Impact of Ethical Leadership, Leadership Effectiveness, Work Related Stress and Turnover Intention on the Organizational Commitment. International Journal of Economics and Business Administration, 2(2), 7-14.

Adams, D., Raman Kutty, G., \& Mohd Zabidi, Z. (2017). Educational Leadership for the 21st Century. International Online Journal of Educational Leadership, 1(1), 14. doi:10.22452//iojel.vol1no1.1.

Amankwaa, A., \& Anku-Tsede, O. (2015). Linking transformational leadership to employee turnover: The moderating role of alternative job opportunity. International Journal of Business Administration, 6(4), 19-29.

Bajwa, E. U., Yousaf, M., \& Rizwan, M. (2014). Employee Turnover Intention in services sector of Pakistan. International Journal of Human Resource Studies, 4(2), 164-180. 
Baron, R. M., \& Kenny, D. A. (1986). The moderator-mediator variable distinction in social psychological research: Conceptual, strategic, and statistical considerations. Journal of Personality and Social Psychology, 51(6), 11731182.

Brown, M. E., Treviño, L. K., \& Harrison, D. A. (2005). Ethical leadership: A social learning perspective for construct development and testing. Organizational behavior and human decision processes, 97(2), 117-134.

Brown, M. E., \& Treviño, L. K. (2006). Ethical leadership: A review and future directions. The Leadership Quarterly, 17(6), 595-616.

Bull, D. A. (2010). Situational leadership style and employee turnover intent: A critical examination of healthcare organizations (Doctoral dissertation, Capella University).

Cropanzano, R., \& Mitchell, M. S. (2005). Social exchange theory: An interdisciplinary review. Journal of Management, 31(6), 874-900.

Dahling, J. J., Chau, S. L., Mayer, D. M., \& Gregory, J. B. (2012). Breaking rules for the right reasons? An investigation of pro-social rule breaking. Journal of Organizational Behavior, 33(1), 21-42.

Demirtas, O. \& Akdogan, A. (2015). The Effect of Ethical Leadership Behavior on Ethical Climate, Turnover Intention, and Affective Commitment. Journal of Business Ethics, 130(1), 59-67.

Elçi, M., Şener, I., Aksoy, S., \& Alpkan, L. (2012). The Impact of Ethical Leadership and Leadership Effectiveness on Employees' Turnover Intention: The Mediating Role of Work Related Stress. Procedia - Social and Behavioral Sciences, 58, 289-297.

George, D., \& Mallery, P. (2003). Reliability analysis. SPSS for Windows, step by step: a simple guide and reference. 14th Ed. Boston: Allyn \& Bacon.

Holtom, B. C., Mitchell, T. R., Lee, T. W., \& Eberly, M. B. (2008). 5 Turnover and Retention Research: A Glance at the Past, a Closer Review of the Present, and a Venture into the Future. The Academy of Management Annals, 2(1), 231274.

Homans, G. C. (1958). Social Behavior as Exchange. American Journal of Sociology, 63(6), 597-606.

Iqbal, M. Z., Arif, I. M., \& Badar, S. (2012). A comparative study of deviant workplace behavior of the teaching staff of public and private universities of PunjabPakistan. International Journal of Asian Social Science, 2(12), 2128-2137.

Jacobs, E., \& Roodt, G. (2008). Organisational culture of hospitals to predict turnover intentions of professional nurses. Health SA Gesondheid, 13(1), 63-78.

Jamshed, S., Mohd Nor, M., \& Abu Bakar, R. (2017). Enhancing Team Effectiveness Through Leader Emotional Intelligence and Knowledge Sharing: Structural Equation Modeling Approach. International Online Journal of Educational Leadership, 1(1), 34-59. doi:10.22452//iojel.vol1no1.3.

Javed, R., Amjad, M., Faqeer-Ul-Ummi, U. Y., \& Bukhari, R. (2014). Investigating Factors Affecting Employee Workplace Deviant Behavior. International Journal of Innovation and Applied Studies, 9(3), 1073-1078.

Johnson, C. E. (2017). Meeting the ethical challenges of leadership: Casting light or shadow (6th ed.). Los Angeles, CA: Sage Publications.

Kacmar, K. M., Bachrach, D. G., Harris, K. J., \& Zivnuska, S. (2011). Fostering good citizenship through ethical leadership: Exploring the moderating role of gender and organizational politics. Journal of Applied Psychology, 96(3), 633642. 
Kaur, B., \& Pankaj, M. (2013). Antecedents of turnover intentions: A literature review. Global Journal of Management and Business Studies, 3(10), 12191230.

Khan, K. E., Khan, S. E., \& Chaudhry, A. G. (2015). Impact of servant leadership on workplace spirituality: Moderating role of involvement culture. Pakistan Journal of Science, 67(1), 109-113.

Kumar, R., Ramendran, C., \& Yacob, P. (2012). A Study on Turnover Intention in Fast Food Industry: Employees' Fit to the Organizational Culture and the Important of their Commitment. International Journal of Academic Research in Business and Social Sciences, 2(5), 9-42.

Majeed, N., Mohd Nor, M., \& Mohd Mustamil, N. (2017). Exploring Relationship Between Transformational Leadership and Organizational Citizenship Behaviors Through Lens of Workplace Spirituality. International Online Journal of Educational Leadership, 1(1), 5-33. doi:10.22452//iojel.vol1no1.2.

Mayer, D. M., Aquino, K., Greenbaum, R. L., \& Kuenzi, M. (2012). Who Displays Ethical Leadership, and Why Does It Matter? An Examination of Antecedents and Consequences of Ethical Leadership. Academy of Management Journal, 55(1), 151-171.

Mobley, W. H. (1977). Intermediate linkages in the relationship between job satisfaction and employee turnover. Journal of applied psychology, 62(2), 237-240.

Morrison, E. W. (2006). Doing the Job Well: An Investigation of Pro-Social Rule Breaking. Journal of Management, 32(1), 5-28.

Muro, M., \& Jeffrey, P. (2008). A critical review of the theory and application of social learning in participatory natural resource management processes. Journal of Environmental Planning and Management, 51(3), 325-344.

Nasir, M., \& Bashir, A. (2012). Examining workplace deviance in public sector organizations of Pakistan. International Journal of Social Economics, 39(4), 240-253.

Neves, P., Story, J. (2015). Ethical Leadership and Reputation: Combined Indirect Effects on Organizational Deviance. Journal of Business Ethics, 127(1), 165176.

Perez, M. (2008). Turnover Intent. Diploma Thesis, University of Zurich. www.hrm.uzh.ch/static/fdb/uploads/da_mylene_perez.pdf

Piccolo, R. F., Greenbaum, R., Hartog, D. N. D., \& Folger, R. (2010). The relationship between ethical leadership and core job characteristics. Journal of Organizational Behavior, 31, 259-278.

Sabir, M. S., Sohail, A., \& Khan, M. A. (2011). Impact of leadership style on organization commitment: In a mediating role of employee values. Journal of Economics and Behavioral Studies, 3(2), 145-152.

Shah, U., \& Khan, J. (2015). An Analysis of the Factors Affecting Turnover Intentions: Evidence from Private Sector Universities of Peshawar. Journal of Social and Administrative Sciences, 2(3), 144-152.

Schaubroeck, J., Lam, S. S., \& Peng, A. C. (2011). Cognition-based and affect-based trust as Mediators of leader behavior influences on team performance. Journal of Applied Psychology, 96(4), 863-871.

Spreitzer, G. M., \& Sonenshein, S. (2004). Toward the Construct Definition of Positive Deviance. American Behavioral Scientist, 47(6), 828-847.

Thau, S., Bennett, R. J., Mitchell, M. S., \& Marrs, M. B. (2009). How management style moderates the relationship between abusive supervision and workplace 
deviance: An uncertainty management theory perspective. Organizational Behavior and Human Decision Processes, 108(1), 79-92.

van Gils, S., Van Quaquebeke, N., van Knippenberg, D., van Dijke, M., \& De Cremer, D. (2015). Ethical leadership and follower organizational deviance: The moderating role of follower moral attentiveness. The Leadership Quarterly, 26(2), 190-203.

Walumbwa, F. O., Hartnell, C. A., \& Misati, E. (2017). Does ethical leadership enhance group learning behavior? Examining the mediating influence of group ethical conduct, justice climate, and peer justice. Journal of Business Research, 72, 14-23.

Wong, P. T. P, \& Page, D. (2003, October). Servant leadership: An opponent process model. Paper presented at the Servant Leadership Roundtable, Regent University, Virginia Beach, VA. Retrieved from http://www.regent.edu/acad/sls/publications/conference_proceedings/serv ant_leadership_roundtab le/2003/proceedings.htm

Xu, S., \& Zhu, J. (2017). Ethical leadership and pro-social rule breaking: A dual process model. Acta Psychologica Sinica, 49(1), 106-115.

Yemi-Sofumade, H. B. (2012). The relationship between ethical and authentic nurse leadership and the turnover intentions of staff nurses (Doctoral dissertation, Capella University).

Youli, H., Xixi, L. U., \& Xi, W. A. N. G. (2014). The Effects of Transformational Leadership on Employee's Pro-social Rule Breaking. Canadian Social Science, 10(1), 128134.

Yukl, G., Mahsud, R., Hassan, S., \& Prussia, G. E. (2013). An improved measure of ethical leadership. Journal of leadership \& organizational studies, 20(1), 3848. 